\title{
Cortico-subthalamic projections in the rat
}

\author{
M. Janssen ${ }^{\text {a,b,c,d, }, \text { V. Visser-Vandewalle }}{ }^{\text {b,c, }}$, Y. Temel ${ }^{\text {a,b,c,d }}$ \\ Departments of ${ }^{a}$ Neuroscience and ${ }^{b}$ Neurosurgery, Maastricht University Medical Center, Maastricht, The Netherlands \\ ${ }^{c}$ Maastricht Institute of Neuromodulative Development (MIND) \\ ${ }^{d}$ European Graduate School of Neuroscience (EURON)
}

\begin{tabular}{|c|c|}
\hline ARTICLF & \\
\hline Article $\mathrm{Hi}$ & \\
\hline Received & $12 / 07 / 2010$ \\
\hline Accepted & $13 / 07 / 2010$ \\
\hline
\end{tabular}

\section{* Correspondence to}

M. Janssen

Department of Neuroscience

Maastricht University

Universiteitssingel 50 (Box 38),

6229 ER, Maastricht. The Netherlands

Email: m.janssen@np.unimaas.nl

\section{Keywords:}

Subthalamic nucleus

Cortex

Tracing

Rodent

Deep brain stimulation

\begin{abstract}
The subthalamic nucleus (STN) is a key structure in the basal ganglia and plays a major role in the pathogenesis of Parkinson's disease. The STN is a popular target for deep brain stimulation (DBS). DBS of the STN improves motor symptoms. Unfortunately, also negative stimulation induced side-effects on behavior and cognition can occur. These side-effects are thought to be caused by direct stimulation of the associative and limbic pathways that run through the STN. In the primate, three functionally segregated parts are clearly described within the STN: a dorsolateral motor part, a medial limbic part and a ventrolateral associative part. In the rodent however, these subdivisions are not well defined. In this review we describe all anterograde cortico-subthalamic tracer studies to map the rodent STN. As a result, a crude functional subdivision in the rodent STN can be made. The lateral two thirds of the STN receive input from the motor and premotor cortex, sparing the medial tip. The medial third receives input from the anterior cingulated, the prelimbic and the agranular insular cortices. There is little evidence for a ventrolateral-dorsomedial subdivision of the medial STN. We conclude that, even though the functional subdivisions are not as clear cut as in the primate STN, a partial anatomical subdivision is present in the rodent STN

J. Exp. Clin. Med., 2010; 27:1
\end{abstract}

\section{Introduction}

The subthalamic nucleus (STN), also known as Corpus Luysii (Hameleers et al., 2006), is a key structure in the basal ganglia. This small lentiform nucleus is embryologically a diencephalic structure, but in the adult brain it is located at the diencephalo-mesencephalic junction (Parent and Hazrati, $1995 b, a)$. In spite of its relatively small size, the STN plays a major role in the pathophysiology of Parkinson's disease (PD): the physiological regular firing pattern of STN neurons changes to a pathological bursty neuronal activity (Bergman et al., 1994, Magill et al., 2000, Ni et al., 2001, Benazzouz et al., 2002, Dostrovsky and Lozano, 2002). The key position of the STN in the basal ganglia and the evident change in its electrical activity in PD, make this nucleus a popular target for neurosurgical therapies such as deep brain stimulation (DBS). Over the last decades, it has been shown consistently that DBS of the STN alleviates motor symptoms and improves quality of life significantly in PD patients (Krack et al., 2003, Rodriguez-Oroz et al., 2004, Visser-Vandewalle et al., 2005, Kleiner-Fisman et al., 2006). However, DBS of the STN can also produce behavioral side-effects (Kleiner-Fisman et al., 2006). In a meta-analysis, it has been shown that in up to $40 \%$ of the patients changes in cognition and mood have been observed (Temel et al., 2006). These changes vary from subtle cognitive changes to major depression with suicidal ideation (Voon et al., 2008). These behavioral side effects of STN DBS are thought to be caused by direct stimulation of the associative and limbic pathways that run through the STN (Temel et al., 2005).

In the primate STN, three functional divisions have been circumscribed: a dorsolateral motor part, a medial limbic part and a ventrolateral associative part (Parent and Hazrati, 1995b, Hamani et al., 2004, Temel et al., 2005). In rodents however, the partition into three separate subdivisions is not entirely clear, despite the fact the rat is often used as an animal model to investigate the motor and non-motor mechanisms of DBS of the STN.

Classically, both the primate and rodent STN receive their input from the globus pallidus externus (GPe), via the multisynaptic cortico-striato-pallido-subthalamic pathway. The primate and rodent STN do not only receive input from basal ganglia nuclei, but they also receive direct afferent input from the cortex. A high density of cortical terminals is present in the STN (Kunzle, 1978, Monakow et al., 1978, Carpenter et al., 1981, Kitai and Deniau, 1981, Jurgens, 1984, Afsharpour, 1985, Rouzaire-Dubois and Scarnati, 1985, Canteras et al., 
1990, Fujimoto and Kita, 1993, Nambu et al., 1996, Nambu et al., 1997, Nambu et al., 2000, Kolomiets et al., 2001, Nambu et al., 2002, Magill et al., 2004, Strafella et al., 2004). These afferent projections from the cortex are also known as the 'hyperdirect' pathway (Nambu et al., 2002). They arise from several functional cortical areas. The major cortical input to the STN is arising from the motor cortex (MC), but also prefrontal cortical areas project directly to the STN. In the primate these cortico-subthalamic loops divide the STN in the three functional subdivisions as mentioned before (Kunzle, 1978, Monakow et al., 1978, Carpenter et al., 1981, Jurgens, 1984, Parent and Hazrati, 1995b, Hamani et al., 2004, Temel et al., 2005). In contrast to the primate, it is not entirely clear how the functional subdivisions are organized in the rat STN.

Here, we have systematically analyzed the studies on the rat cortico-subthalamic projections. Our aim was to describe the functional subdivisions of the rat STN by looking at the origins of the cortical afferents. We only included anterograde tracer studies with injection sites in the cortex. We excluded studies with retrograde tracer injections in the STN, since the tracer can be taken up by neighboring structures and it can diffuse to other STN subdivisions.

\section{Material and method}

\section{Search strategy}

A structured Medline (Pubmed) search was performed including articles published up until December 2008. The following key words were used: STN, subthalamic nucleus, subthalamic in combinations with motor cortex (MC), MC, cortex, cortical, cort* and tracing, anterograde, phaseolus, biotinylated dextran amine (BDA), BDA, and rat or rodent. All references in the reviewed articles were checked to find additional studies.

\section{Study Selection}

All studies were reviewed independently by two investigators. Studies were selected according to the following criteria. Only studies with a rodent as a subject were included. We excluded tracing studies in other species, like primates and cats. Studies were included if the injection site was in the cortex and if an anterograde tracer was used. Tracing studies which only made use of retrograde tracing techniques or an injection outside the cortex were excluded. In total 10 studies were selected. The results as well as the figures were systematically and extensively studied by the investigators.

\section{Results}

Projections from the motor and premotor cortical areas The projection from MC to the STN in the rodent was probably for the first time extensively descrived by Afsharpour (1985). In his tracing experiments he injected 0.25-4 $\mu$ l of $3 \mathrm{H}$-proline/3Hleucine or $3 \mathrm{H}$-lycine/3H-leucine using a Hamilton microsyringe according to the cortical parcellation by Hall and Lindholm (1974) and Donoghue and Wise (1982). Four injections in the rostral part of the lateral agranular cortex (M1) (coordinates from Bregma: anterioposterior [AP] 5.5mm, mediolateral [ML] 2.8mm until AP 2.3, ML 4.5mm, ventrality not provided, animal weights were $230-488 \mathrm{~g}$ ) resulted in tracer signal in the lateral two thirds of the rostral STN with the greatest concentration of the tracer in the dorsolateral tip of the STN (table 1). Injections in the medial part of the lateral agranular cortex (coordinates from Bregma: AP 5.8, ML 1.9 until AP -0.5, ML 3.0, ventrality not provided) resulted in a more band-shaped labeling confined to the ventral aspect of the rostral STN and seemed to shift dorsally at the caudal part of the STN. Injections in the caudal part of the lateral agranular cortex (coordinates from Bregma: AP -1.0mm, ML $2.5 \mathrm{~mm}$, ventrality not provided) however, induced only faint labeling in the ventral part of the middle third of the STN. Furthermore, the results showed that the rostral part of the medial agranular cortex (M2) (coordinates from Bregma: AP $+5.8 \mathrm{~mm}$, ML 1.9 until AP $-0.5 \mathrm{~mm}$, ML $3.0 \mathrm{~mm}$, ventrality not provided) projected to the ventral two thirds of the medial third of the STN and extended rostrocaudally (fig. 1).

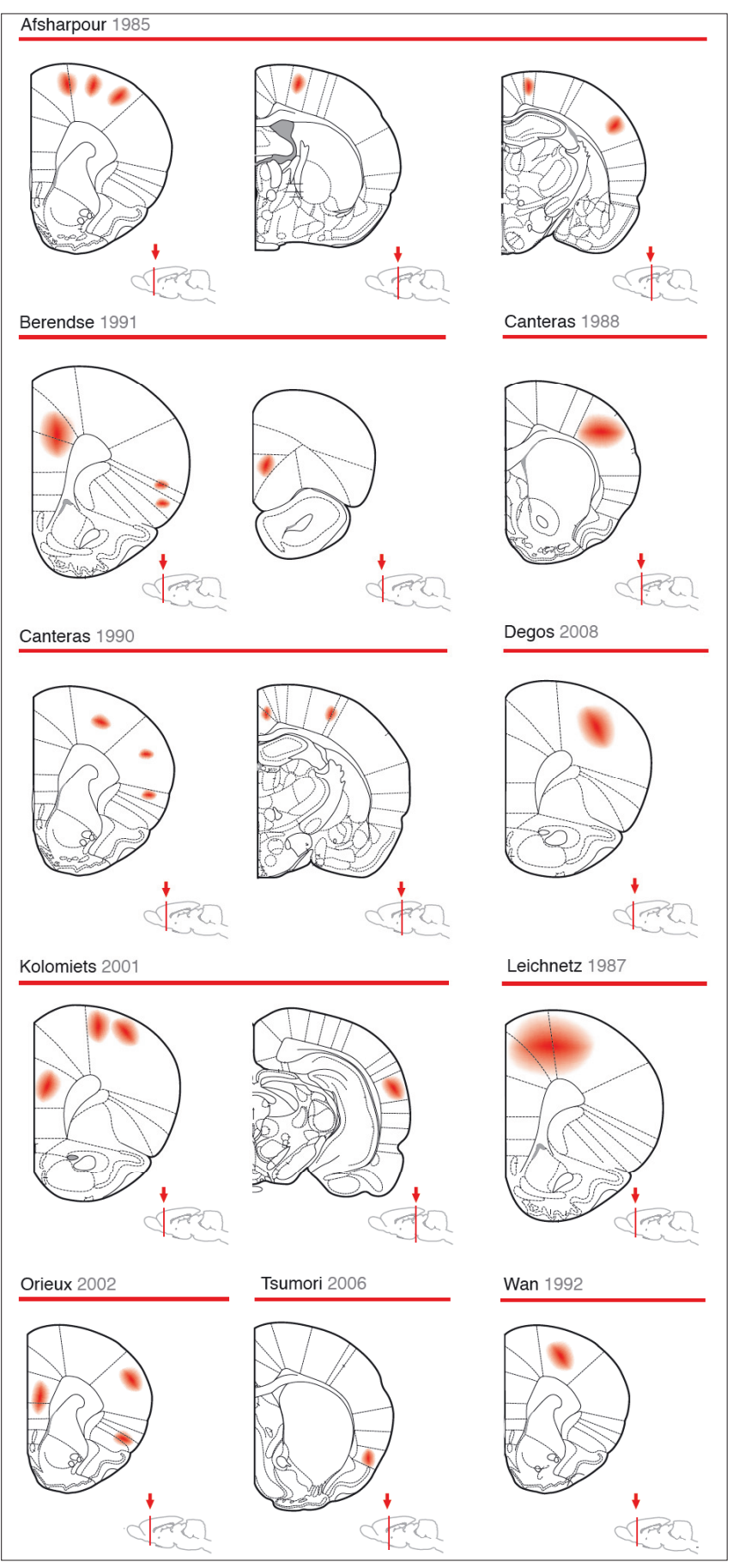

Fig. 1. Overview of the estimated injection or implantation sites in the different cortical regions of the rat. The red areas represent the injection sites in coronal sections of the brain. The red line in the sagital sections shows the estimated anteroposterior level of the coronal section. 
In 1990, micro-electrophoretic injections of wheat germ agglutinin-horseradish peroxidase (WGA-HRP) in the rostral parts of the primary motor cortex (M1) (coordinates: not provided; atlas: not mentioned; animal weights: 170-200g) were performed by Canteras et al. (1990). Labeling was seen in the rostral two thirds, but not in the ventromedial tip, of the STN. After a more extensive injection in the MC also labeling in the lateral half of the caudal third of the STN was present.

Wan et al. (1992) injected leucoagglutinin (PHA-L) into the caudal forelimb region of the MC (coordinates: not provided; atlas: not mentioned; animal weights: $150-300 \mathrm{~g}$ ) by iontophoresis. They found tracer signal in the STN without describing a further topographical organization.

By using iontophoretic injections of WGA-HRP into the orofacial and forelimb areas of M1, labeling was seen in the more lateral parts of the STN. The orofacial injections (authors used coordinates from the interaural line, re-calculated coordinates from Bregma: AP $+3.5 \mathrm{~mm}$, ML 3.8mm and ventral [V] $-1.5 \mathrm{~mm}$ from the cortical surface; atlas: Paxinos and Watson, edition 2, 1986; animal weights: 270-300g) resulted in tracer signal in the central part of the mediolateral extension of the STN, whereas injections in the forelimb area of M1 (re-calculated coordinates from Bregma: AP $+3.0 \mathrm{~mm}$, ML $2.3 \mathrm{~mm}$ and $\mathrm{V}-1.5 \mathrm{~mm}$ from the cortical surface) projected more ventrally and caudally, sparing the medial and lateral parts of the STN (Paxinos and Watson, 1986, Kolomiets et al., 2001).

In a more recent study, Degos et al. ( 2008) injected iontophoretically PHA-L in the orofacial motor area of M1 (authors used coordinates from the interaural line, re-calculated coordinates from Bregma: $\mathrm{AP}+3.5 \mathrm{~mm}, \mathrm{ML}+3.8 \mathrm{~mm}$ and $\mathrm{V}$ $-1.2 \mathrm{~mm}$; atlas: Paxinos and Watson, edition 2 (1986); animal weights: $300-360 \mathrm{~g}$ ) . Tracer signal was seen in the caudal two thirds of the STN, in the lateral part of the medial third of the STN and more to the medial side in the caudal third. The ventromedial tip remained free of tracer.

\section{Projections from the prelimbic cortex}

Only in a few anatomical studies an anterograde tracer was injected into the prelimbic cortex in order to determine the projection to the STN. The oldest publication which we have found about the projections from the prelimbic cortex to the STN showed tracer signal in the medial STN (Leichnetz et al., 1987). The authors used a pellet of HRP-gel. The pellet was implanted in the dorsomedial frontal shoulder cortex (coordinates: not provided; atlas: not mentioned; animal weights: not provided), which encompasses the medial precentral and anterior cingulate cortices. The anatomical data showed heavy labeling in the dorsomedial STN.

A study by Berendse and Groenewegen (1991) using PHA-L as an anterograde tracer showed labeling in the caudal part of the most medial part of the STN after pressure injections in the dorsal part of the prelimbic cortex (coordinates from Bregma: not provided; atlas: not mentioned; animal weights: not provided). After injection in the ventral part of the prelimbic cortex (coordinates from Bregma: not provided), tracer signal was only visualized in the adjacent LH and not in the STN.

Kolomiets et al. (2001) injected WGA-HRP into the prelimbic medial orbital areas of the prefrontal cortex (authors used coordinates from the interaural line, re-calculated coor- dinates from Bregma: AP $+3.5 \mathrm{~mm}$, ML $0.4 \mathrm{~mm}$ and $\mathrm{V}-3.5 \mathrm{~mm}$ from the cortical surface; atlas: Paxinos and Watson, edition 2, (1986); animal weights: 270-300g) using iontophoresis. The anterograde tracer was only present in the medial third of the rat STN.

Later, Orieux et al (2002) showed scattered positive fibers in the medial part of the STN. Fibers were seen in almost the entire anteroposterior extent of the medial STN. The authors injected BDA in the prelimbic/ medial orbital cortex according to us. This is in contrast to the opinion of the author himself who stated that the iontophoresis was in the cingulate cortex (coordinates from Bregma: AP $+3.5 \mathrm{~mm}$, ML $0.5 \mathrm{~mm}$ and V $-3.0 \mathrm{~mm}$ from the cortical surface; atlas: Paxinos and Watson, edition 4, (1998); animal weights: 250-300g).

\section{Projections from the anterior cingulate cortex}

One of the first studies describing a projection from the anterior cingulate cortex to the STN was by Leichnetz et al. (1987). The pellet of HRP-gel in the dorsomedial shoulder cortex (coordinates: not provided; atlas: not mentioned; animal weights: not provided) resulted in tracer signal in the medial STN.

A study using PHA-L demonstrated labeling of the ventral and lateral parts of the medial STN, most densely at the caudal levels. The tracer was injected with a pump into the dorsal anterior cingulate cortex (coordinates: not provided; atlas: not mentioned; animal weights: not provided) (Berendse and Groenewegen, 1991).

\section{Projections from the insular cortex}

Canteras et al. (1990) injected WGA-HRP into the granular insular cortex using micro-electrophoretic deposits and found small varicosities in the dorsomedial narrow strip of the STN (coordinates from Bregma: not provided; atlas: not mentioned; animal weights: 170-200g).

A study by Berendse and Groenewegen (1991) described the afferent projections after injection of PHA-L into the dorsal agranular insular and the ventral agranular insular cortices (coordinates: not provided; atlas: not provided; animal weights: not provided). Tracer signal was only seen in the lateral hypothalamic area, but not in the STN, after injection in the ventral agranular insular cortex. In contrast, fibers were seen in the rostral part of the STN in animals with an injection of BDA into the dorsal agranular cortex.

An iontophoretic deposit of BDA the dorsal agranular insular cortex (coordinates from Bregma: AP $+2.0 \mathrm{~mm}, \mathrm{ML}$ $5.0 \mathrm{~mm}$ and V $-4.5 \mathrm{~mm}$ from the cortical surface; atlas: Paxinos and Watson, edition 4, (1998); animal weight: 250-300g) induced weak labeling in the anterior portion of the STN, occupying the entire mediolateral extent (Orieux et al., 2002). A third study with an injection of BDA into the insular cortex (coordinates from Bregma: AP $0.0--0.5 \mathrm{~mm}$, ML $5.6-$ $6.0 \mathrm{~mm}$ and V -7.0 - -7.6mm; atlas: Paxinos and Watson, edition 5, (2005); animal weight: 230-300g) using iontophoresis showed no tracer in the STN (Tsumori et al., 2006).

\section{Projections from the somatosensory cortex}

Afsharpour (1985) was one of the first to look at the projections from the somatosensory cortex in the rat. He injected the $3 \mathrm{H}$-proline $/ 3 \mathrm{H}$-leucine or $3 \mathrm{H}$-lycine $/ 3 \mathrm{H}$-leucine tracer into the caudal granular somatosensory cortex according to 


\begin{tabular}{|c|c|c|c|c|c|c|}
\hline Autors & Year & Journal & Injection site & Bregma & STN & Method \\
\hline Afsharpour $\mathrm{S}$. & 1985 & J Comp Neurol & $\begin{array}{l}\text { Rostral part of the lateral } \\
\text { agranular cortex }\end{array}$ & $\begin{array}{l}\text { AP } 5.5, \mathrm{ML} 2.8 \\
\text { until AP 2.3, ML } 4.5 \text {, } \\
\text { V not provided }\end{array}$ & $\begin{array}{l}\text { Lateral } 2 / 3 \text { of the rostral STN; greatest } \\
\text { concentration at the dorsolateral tip. }\end{array}$ & $\begin{array}{l}\text { Hamilton } 0.25-4 \mu 1 \\
\text { 3H-proline/3H-leucine or } \\
\text { 3H-lycine/3H-leucine }\end{array}$ \\
\hline & & & $\begin{array}{l}\text { Caudal part of the lateral } \\
\text { agranular cortex (or the } \\
\text { rostral part of the parietal } \\
\text { cortex) }\end{array}$ & $\begin{array}{l}\text { AP - } 1.0, \text { ML } 2.5 \\
\text { V not provided }\end{array}$ & $\begin{array}{l}\text { Faint labeling in the ventral aspect of the } \\
\text { middle third of STN. }\end{array}$ & $\begin{array}{l}\text { Hamilton } 0.25-4 \mu 1 ; \\
\text { 3H-proline/3H-leucine or } \\
\text { 3H-lycine/3H-leucine }\end{array}$ \\
\hline & & & $\begin{array}{l}\text { Caudal part of the medial } \\
\text { agranular cortex }\end{array}$ & $\begin{array}{l}\text { AP }-3.0, \text { ML } 1.5 \\
\text { V not provided }\end{array}$ & $\begin{array}{l}\text { Faint projections. dorsolateral portion of the } \\
\text { caudal two-thirds of the STN }\end{array}$ & $\begin{array}{l}\text { Hamilton } 0.25-4 \mu 1 ; \\
\text { 3H-proline/3H-leucine or } \\
\text { 3H-lycine/3H-leucine }\end{array}$ \\
\hline & & & $\begin{array}{l}\text { Granular somatosensory } \\
\text { cortex / occipital areas }\end{array}$ & $\begin{array}{l}\text { AP - } 2.5, \text { ML } 6.0, \\
\text { V not provided/AP } \\
2.5\end{array}$ & No STN labeling & $\begin{array}{l}\text { Hamilton } 0.25-4 \mu 1 \text {; } \\
\text { 3H-proline/3H-leucine or } \\
\text { 3H-lycine/3H-leucine }\end{array}$ \\
\hline \multirow[t]{3}{*}{$\begin{array}{l}\text { Leichnetz GR, Hardy SG, } \\
\text { Carruth, MK. }\end{array}$} & 1987 & J Comp Neurol & $\begin{array}{l}\text { Medial precentral and } \\
\text { anterior cingulate }\end{array}$ & not provided & $\begin{array}{l}\text { Heavy labeling in the dorsal medial } \\
\text { subthalamic region }\end{array}$ & Pellet of HRPgel \\
\hline & & & $\begin{array}{l}\text { Right rostral dorsomedial } \\
\text { frontal shoulder cortex, } \\
\text { mainly medial precentral } \\
\text { and anterior cingulate, but } \\
\text { spread to lateral precentral } \\
\text { and dorsal orelimbic area } \\
\text { (PFC15) }\end{array}$ & not provided & $\begin{array}{l}\text { Notheworthy projection in STN, dorsal medial } \\
\text { subthalamic region ellipsoid-shaped } \\
\text { concentration of labeling }\end{array}$ & Pellet of HRPgel \\
\hline & & & $\begin{array}{l}\text { Middle dorsomedial } \\
\text { shoulder region, but with } \\
\text { more spread caudally than } \\
\text { PFC 15 (PFC 17) }\end{array}$ & not provided & Medial subthalamic region & Pellet of HRPgel \\
\hline $\begin{array}{l}\text { Canteras NS, Shammah- } \\
\text { Lagnado SJ, Silva BA, } \\
\text { Ricardo JA. }\end{array}$ & 1988 & Brain Res & $\begin{array}{l}\text { Primary somatosensory } \\
\text { cortex. rostral half of this } \\
\text { cortical district }\end{array}$ & not provided & $\begin{array}{l}\text { Dorsolateral sector at the midrostrocaudal level } \\
\text { of the STN, but also with lesser density in the } \\
\text { dorsal part of the rostral portion and the } \\
\text { dorsolateral tip of the caudal district }\end{array}$ & Iontophoresis; WGA-HRP \\
\hline \multirow[t]{4}{*}{$\begin{array}{l}\text { Canteras NS, Shammah- } \\
\text { lagnado SJ, Silva BA, } \\
\text { Ricardo JA }\end{array}$} & 1990 & Brain Res & $\begin{array}{l}\text { Rostral parts of the } \\
\text { primary motor area }\end{array}$ & not provided & $\begin{array}{l}\text { Rostral } 2 / 3 \text { part of the STN;no labeling in a } \\
\text { small ventromedial sector of the STN }\end{array}$ & $\begin{array}{l}\text { Micro-electrophorectic; } \\
\text { WGA-HRP }\end{array}$ \\
\hline & & & $\begin{array}{l}\text { Extensive injection area in } \\
\text { MC }\end{array}$ & not provided & $\begin{array}{l}\text { Additional conspicous labeling of the lateral } \\
\text { half of the caudal third of the STN }\end{array}$ & $\begin{array}{l}\text { Micro-electrophorectic; } \\
\text { WGA-HRP }\end{array}$ \\
\hline & & & $\begin{array}{l}\text { Primary somatosensory } \\
\text { cortex, rostral half of the } \\
\text { primary somatosensory } \\
\text { cortex }\end{array}$ & not provided & Anterograde & $\begin{array}{l}\text { Micro-electrophorectic; } \\
\text { WGA-HRP }\end{array}$ \\
\hline & & & $\begin{array}{l}\text { Caudal half of the primary } \\
\text { somatosensory cortex }\end{array}$ & not provided & Few, if any, labeling in STN & $\begin{array}{l}\text { Micro-electrophorectic; } \\
\text { WGA-HRP }\end{array}$ \\
\hline \multirow[t]{8}{*}{$\begin{array}{l}\text { Berendse HW, } \\
\text { Groenewegen HJ. }\end{array}$} & 1991 & $\begin{array}{l}\text { The basal ganglia III. } \\
\text { New York: Plenum. }\end{array}$ & Prefrontal cortex & not provdided & labeling in ipsilateral STN and/or adjacent LH & Pressure injection; PHA-L \\
\hline & & & $\begin{array}{l}\text { dorsal anterior cingular } \\
\text { cortex }\end{array}$ & not provdided & $\begin{array}{l}\text { ventrally and laterally in de medial part of the } \\
\text { STN, most densely at caudal levels }\end{array}$ & Pressure injection; PHA-L \\
\hline & & & $\begin{array}{l}\text { dorsal part of the } \\
\text { prelimbic cortex }\end{array}$ & not provdided & $\begin{array}{l}\text { caudally in the most medial part of the STN, } \\
\text { with a few fibers in the adjacent LH }\end{array}$ & Pressure injection; PHA-L \\
\hline & & & $\begin{array}{l}\text { ventral part of the } \\
\text { prelimbic cortex }\end{array}$ & not provdided & no tracer in STN, only in the LH & Pressure injection; PHA-L \\
\hline & & & $\begin{array}{l}\text { dorsal agranular insular } \\
\text { cortex }\end{array}$ & not provdided & $\begin{array}{l}\text { rostral part of the STN. At the rostral extreme } \\
\text { the fibers occupy a ventral position, whereas } \\
\text { somenwat more caudally they shift to a } \\
\text { dorsomedial position }\end{array}$ & Pressure injection; PHA-L \\
\hline & & & medial orbital & not provdided & $\begin{array}{l}\text { no tracer in STN, projections confined to the } \\
\text { LH }\end{array}$ & Pressure injection; PHA-L \\
\hline & & & infralimbic & not provdided & $\begin{array}{l}\text { no tracer in STN, projections confined to the } \\
\text { LH }\end{array}$ & Pressure injection; PHA-L \\
\hline & & & $\begin{array}{l}\text { ventral agranular insular } \\
\text { cortices }\end{array}$ & not provdided & $\begin{array}{l}\text { no tracer in STN, projections confined to the } \\
\text { LH }\end{array}$ & Pressure injection; PHA-L \\
\hline $\begin{array}{l}\text { Wan XST, Liang F, Moret } \\
\text { V, Wiesendanger M, } \\
\text { Rouiller EM. }\end{array}$ & 1992 & Neuroscience & $\begin{array}{l}\text { Caudal forelimb cortical } \\
\text { area of the motor cortex }\end{array}$ & not provided & STN (not further defined) & $\begin{array}{l}\text { Iontophoresis; PHA-L/ } \\
\text { biocytin }\end{array}$ \\
\hline \multirow[t]{5}{*}{$\begin{array}{l}\text { Kolomiets BP, Deniau } \\
\text { JM, Mailly P, Menetrey } \\
\text { A, Glowinski J, Thierry } \\
\text { AM. }\end{array}$} & 2001 & J Neurosci & $\begin{array}{l}\text { Prelimbic medial orbital } \\
\text { areas of the prefrontal } \\
\text { cortex (PL-MO) }\end{array}$ & $\begin{array}{l}\mathrm{AP} 3.5, \mathrm{ML} 0.4, \mathrm{~V} \\
3.5 \mathrm{c}\end{array}$ & Medial third & Iontophoresis; WGA-HRP \\
\hline & & & Orofacial and forelimb & see below & More laterally & Iontophoresis; WGA-HRP \\
\hline & & & Orofacial motor cortex & $\begin{array}{l}\text { AP } 3.5, \text { ML } 3.8, \mathrm{~V} \\
1.5 \mathrm{c}\end{array}$ & $\begin{array}{l}\text { Rostral half of the STN where they occupied } \\
\text { the central part of the mediolateral extension of } \\
\text { the structure }\end{array}$ & Iontophoresis; WGA-HRP \\
\hline & & & Forelimb motor area & $\begin{array}{l}\mathrm{AP} 3.0, \mathrm{ML} 2.3, \mathrm{~V} \\
1.5 \mathrm{c}\end{array}$ & $\begin{array}{l}\text { More ventrally and caudally, sparing the medial } \\
\text { and the most lateral part of the STN }\end{array}$ & Iontophoresis; WGA-HRP \\
\hline & & & Auditory cortex & $\begin{array}{l}\mathrm{AP}-5.5, \mathrm{ML} 7.2, \mathrm{~V} \\
2.0 \mathrm{c}\end{array}$ & No labeling & Iontophoresis; WGA-HRP \\
\hline \multirow[t]{3}{*}{$\begin{array}{l}\text { Orieux G, Francois C, } \\
\text { Feger J, Hirsch EC. }\end{array}$} & 2002 & J Neurosci & Somatosensory cortex & $\begin{array}{l}\text { AP } 1.0, \mathrm{ML} \pm 4.5, \mathrm{~V}- \\
3.2 \mathrm{c}\end{array}$ & $\begin{array}{l}\text { No tracer in STN, tracer in the ventral zone of } \\
\text { the ZI }\end{array}$ & Ionthophoresis; BDA \\
\hline & & & $\begin{array}{l}\text { prelimbic and medial } \\
\text { orbital cortex* }\end{array}$ & $\begin{array}{l}\text { AP } 3.5, \mathrm{ML} \pm 0.5, \mathrm{~V}- \\
3.0 \mathrm{c}\end{array}$ & $\begin{array}{l}\text { Scattered possitive fibers in the medial part of } \\
\text { the STN, almost throughout its anteroposterior } \\
\text { extent. }\end{array}$ & Ionthophoresis; BDA \\
\hline & & & Dorsal insular cortex & $\begin{array}{l}\mathrm{AP} 2.0, \mathrm{ML} \pm 5.0, \mathrm{~V}- \\
4.5 \mathrm{c}\end{array}$ & $\begin{array}{l}\text { Weak labeling restricted to the most anterior } \\
\text { portion of the STN occupying the whole } \\
\text { mediolateral extent, with a shift, more caudally, } \\
\text { to a dorsal localization }\end{array}$ & Ionthophoresis; BDA \\
\hline $\begin{array}{l}\text { Tsumori T, Yokota S, } \\
\text { Kishi T, Qin Y, Oka T, } \\
\text { Yasui Y. }\end{array}$ & 2006 & Brain Res & Insular cortex & $\begin{array}{l}\text { AP } 0.0-0.3, \mathrm{ML} \\
5.6-6.0, \mathrm{~V} 7.0-7.6 \mathrm{c}\end{array}$ & No tracer in STN, only medial to the STN & Ionthophoresis; BDA \\
\hline $\begin{array}{l}\text { Degos B, Deniau JM, Le } \\
\text { Cam J, Mailly P, Maurice } \\
\mathrm{N}\end{array}$ & 2008 & Eur J Neurosci & $\begin{array}{l}\text { Antero-lateral M1 motor } \\
\text { area (orofacial territory) }\end{array}$ & $\begin{array}{l}\mathrm{AP} 3.5, \mathrm{ML} 3.8, \mathrm{~V} \\
1.2 \mathrm{c}\end{array}$ & $\begin{array}{l}\text { Anterior half of the STN } \\
\text { (occupied whole latero-medial extension, more } \\
\text { caudal in central and lateral position). Mainly in } \\
\text { dorsal half. }\end{array}$ & $\begin{array}{l}\text { Iontophoresis } 8-10 \mu 1 \text {; } \\
\text { PHA-L }\end{array}$ \\
\hline
\end{tabular}

Table 1. In this table an overview is given of all the injection sites per author, with the corresponding tracing site in the subthalamic nucleus. The anatomical description of the injection sites and the (re-calculated) coordinates from Bregma are shown if provided. Also the technique and tracer used are given. anteroposterior (AP), mediolateral (ML), ventrality (V), ventrality measured from the cortex (c). *Anatomical injection site based on figure in original article. 
the cortical parcellation by Hall and Lindholm (1974) and Donoghue and Wise (1982) (coordinates from Bregma: AP $-2.5 \mathrm{~mm}$, ML 6.0mm, ventrality not provided; animal weighst: $230-488 \mathrm{~g})$. In his experiment there was no labeling in the STN. However, Canteras et al. $(1988,1990)$ injected WGAHRP iontophoretically into the rostral half of the primary somatosensory cortex (coordinates: not provided; atlas: not mentioned; animal weights: 170-200g) and found positive fibers in the dorsolateral part at the midrostrocaudal level of the STN, but also with a lesser density in the dorsal part of the rostral portion and the dorsolateral tip of the caudal district. In a follow-up experiment they injected WGA-HRP into the caudal half of the primary somatosensory cortex (coordinates: not provided; atlas: not provided; animal weights: 170-200g) using iontophoresis and found only few, if any, labeling in the STN (Canteras et al., 1990). In 2002, for a second time a tracer study with BDA did not show any labeling in the STN after iontophoretic injection of the dye into somatosensory cortex (coordinates from Bregma: AP $+1.0 \mathrm{~mm}$, ML $4.5 \mathrm{~mm}$ and $\mathrm{V}$ $-3.2 \mathrm{~mm}$ from the cortical surface; atlas: Paxinos and Watson, edition 4, (1998); animal weights: 250-300g) (Orieux et al., 2002).

\section{Projections from other cortical areas}

Some studies have investigated the afferent input to STN from other cortical areas. No labeling was found in the STN after tracer injections in the retrosplenial cortex, and primary visual and primary auditory cortices (Canteras et al., 1990, Kolomiets et al., 2001). Again no STN labeling was found after injections of PHA-L into the medial orbital and infralimbic cortex (Berendse and Groenewegen, 1991).

\section{Discussion}

\section{The functional subdivisions of the rat STN}

The reviewed data demonstrate the existence of a rough subdivision system in the rat STN. Several parallel projections from the cortex to the rodent STN are present. The most important projections originate from the motor and premotor cortex (Afsharpour, 1985, Canteras et al., 1990, Wan et al., 1992, Kolomiets et al., 2001, Degos et al., 2008), cingulate cortex (Leichnetz et al., 1987, Berendse and Groenewegen, 1991, Orieux et al., 2002), prelimbic (Leichnetz et al., 1987, Berendse and Groenewegen, 1991, Kolomiets et al., 2001), and the agranular insular cortex (Berendse and Groenewegen, 1991, Orieux et al., 2002). Afferent fibers from the motor cortex and the pre-motor cortex project to the lateral two thirds of the rat STN, thereby sparing the medial tip. The medial third of the STN receives input from the anterior cingulate, the prelimbic and the agranular insular cortices. There is little evidence for a ventrolateral-dorsomedial subdivision of the medial STN (Berendse and Groenewegen, 1991). The ventrolateral division of the medial third receives its input mainly from the anterior cingulate cortex, whereas the projection from the pre-limbic and agranular insular cortex is restricted to the dorsomedial part (fig. 2).

\section{Differences between the studies}

There are some evident differences in the results between the various anatomical studies. They may result from the variances in the method of injection, injection sites and tracers used. We will elaborate on the main dissimillarities found per cortical injection site.

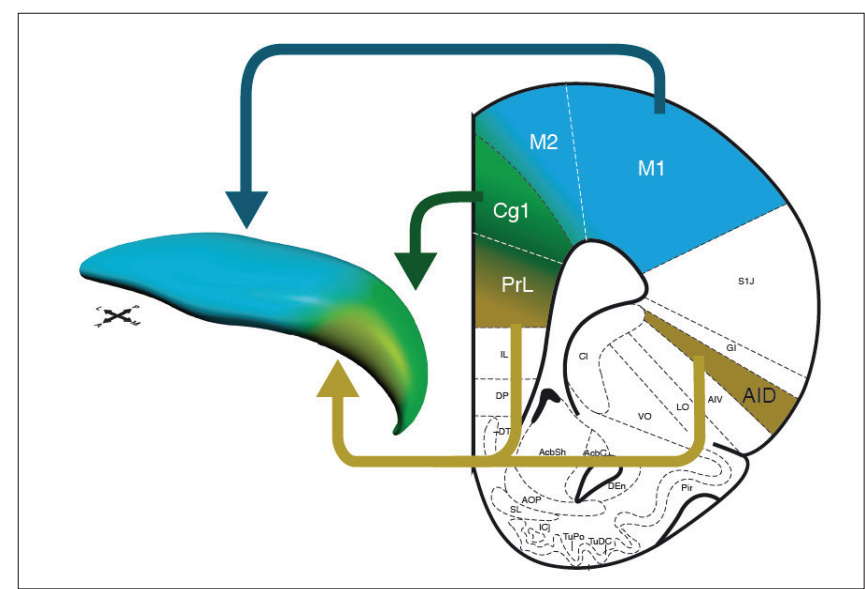

Fig. 2. This figure illustrates the functional subdivisions of the rodent STN. The nucleus has anatomically two major subdivisions: the lateral two-thirds consist of the motor part (blue) and the medial third is the limbic/ associative part (green/ yellow). These divisions are not strictly segregated but partially overlapping. Thereby small evidence is present for an anatomical organization of the medial part. The arrows show the cortical projections to the different subthalamic subdivisions.

Berendse and Groenewegen (1991) only observed labeling in the dorso-medial part of the STN after injection in the cingulate gyrus, though Leichnetz et al. (1987) found tracer in the whole medial STN. The findings of Leichnetz et al. (1987) could be due to the use of relatively big pellets, making their method less accurate. A high-quality methodological tracer study is needed to see whether the cingulate gyrus projects to the entire medial STN or that its projection is strictly focused to the dorso-medial part of the medial STN.

Another discrepancy is present between the studies about the projections from the prelimbic cortex to the medial STN. Kolomiets et al. (2001) showed tracing to the medial part of STN from the dorsomedial frontal shoulder cortex involving the prelimbic, but also the cingulate cortex. The injection of Orieux et al. (2002) in the medial prefrontal cortex, according to us mainly in the prelimbic and medial orbital cortices, gave labeling throughout the whole anteroposterior extent of the medial STN. This was in contradiction with the iontophoretic study of Berendse and Groenewegen (1991) who only found labeling in the dorsomedial part.

The dorsal part of the agranular insular cortex seems to project to the dorsomedial part of the STN. Canteras et al. (1990) described this after injection into the granular cortex, and both Berendse and Groenewegen (1990) as well as Orieux et al. (2002) showed the same after an injection into the dorsal agranular insular cortex. Tsumori et al. (2006) did not observe a projection from the insular cortex. This implicates that the results from Canteras et al. (1990) may perhaps be a result of diffusion of the tracer to the dorsal agranular cortex. The ventral part of the agranular insular cortex also doesn't seem to project to the STN, but only to the adjacent LH.

There is only little evidence that the somatosensory cortex projects to the STN. Canteras et al. (1988) found some projections from the caudal half of the somatosensory cortex but this is in contradiction to the findings of Afsharpour (1985) and Orieux (2002). The findings of Canteras et al. (1988) could again be due to leakage of the tracer to the motor cortical areas. 


\section{Similarities between the studies}

There were also evident consistencies. For instance, injections in the motor areas never resulted in labeling in the medial part of the STN. Only Afsharpour (1985) mentioned labeling in the medial part of the STN after injection in the agranular cortex. If looked carefully to the injection sites of this study, diffusion of the tracer to the prefrontal areas like the cingulate gyrus cannot be ruled out.

Another challenge encountered in this review was the fact that some authors used different descriptions for the same anatomical site and did not always provide the stereotactic coordinates and relevant images.

\section{Correlation between the cortico-subthalamic and subcor- tico- subthalamic projections}

The topography of the rat STN based on the cortico-subthalamic projections matches with the input from the subcortical regions. The lateral STN receives input from the lateral part of the parafascicular thalamic nucleus (Sugimoto et al., 1983, Groenewegen and Berendse, 1990), which also projects to the lateral part of the caudate putamen $(\mathrm{CPu})$. The lateral $\mathrm{CPu}$ indirectly projects to the lateral STN via the lateral part of the globus pallidus (GP: equivalent of the GPe in primates) (Ricardo, 1980, Gerfen, 1985, Kita and Kitai, 1987). The medial part of the STN receives its input from the most medial part of the parafascicular thalamic nucleus, which also projects to the nucleus accumbens (NAc) and the medial $\mathrm{CPu}$. The $\mathrm{NAc}$ and the medial $\mathrm{CPu}$ project indirectly to the medial STN via respectively the lateral part of the subcommisural ventral pallidum and the medial part of the GP (Berendse and Groenewegen, 1990, Maurice et al., 1998). The NAc, in turn, receives input from the prefrontal cortex. It seems that the functionally different cortical areas project both in a 'hyperdirect' and indirect way to the STN in a parallel organized manner. Moreover, the efferent output of the STN to the GP, entepeduncular nucleus (EP: equivalent of the GPi in primates) and the ventral pallidum matches with the subdivisions based on the cortico-subthalamic tracer studies. The lateral STN mainly projects to the lateral GP and EP, whereas the medial part projects to the ventral pallidum and the medial GP and EP in the rat (Kita and Kitai, 1987, Groenewegen and Berendse, 1990, Maurice et al., 1998).

\section{Cortical afferents}

Our findings from the reviewed data suggest that the cortical projections to the rat STN follow a specific pattern of innervation. The major input arises from the motor and premotor areas. The afferent projections from the motor cortex arise mainly from layer V (Kitai and Deniau, 1981, Gradinaru et al., 2009) and are collaterals of the pyramidal tract or from fibers that also project to the striatum. In addition, projections arise from the prelimbic (Leichnetz et al., 1987, Berendse and Groenewegen, 1991, Kolomiets et al., 2001), anterior cingulate (Leichnetz et al., 1987, Berendse and Groenewegen, 1991, Orieux et al., 2002) and dorsal agranular insular cortex (Berendse and Groenewegen, 1991, Orieux et al., 2002). The terminals of the cortical axons make contact with small dendrites and cell bodies of STN neurons and use glutamate as neurotransmitter.

The rat STN does not receive input from the ventral agranular and the granular insular, retrosplenial, primary visual and primary auditory, medial orbital and infralimbic cortices and probably also not from the somatosensenory cortex. Also noticeable is that not all cortical areas which are involved in associative and/ or limbic functions project directly to the STN.

\section{Integration of the motor, limbic and associative projec- tions in the STN}

In agreement with the anatomical tracing studies, electrophysiological studies demonstrate a functional subdivision as well. Neurons that respond to cortical stimulation were found in the anatomically defined territories of the STN (Maurice et al., 1998, Kolomiets et al., 2001, Magill et al., 2004). Nevertheless, it seems unlikely that the subdivisions of the rat STN are entirely segregated from each other. The rat STN has a higher number of neurons per cubic millimeter $(30,000$ cells per $\mathrm{mm} 3)$ compared to the primate and human STN $(2,300$ cells per mm3) (Hardman et al., 2002). Moreover, the dendrites can extend across almost the entire STN (Heimer et al., 1995). An extra argument is that a 'hyperdirect' response to stimulation of the prelimbic cortex is seen in 7\% of the STN cells which also respond to motor cortex stimulation (Kolomiets et al., 2001). Despite these noteworthy differences between the rat STN and the (human) primate STN the internal organization and its place in the basal ganglia is highly comparable.

\section{Limitations and methodological considerations}

Only ten studies could be identified in which an anterograde tracer was injected in a cortical area and the tracer signal was analysed in the STN. Due to the low number of studies, we also included papers in which the neuroanatomical tracing of the corticosubthalamic projection was only a part of a broader study.

Various tracing techniques have been used in the studies reviewed here. Several authors have used tritiated amino acids or WGA-HRP. By using these tracers, it is not possible to distinguish between terminating or passing fibers. Others have used BDA which gives a very good labeling, but can be taken up by passing fibers or transported retrogradely. PHA-L has also been used and is a very specific anterograde tracer (Reiner et al., 2000). The variety of techniques used, complicates the comparison between the studies. Therefore, we think that the results of the individual studies must be handled with care.

Another factor that needs to be taken into account is that the nomenclature of the different cortical areas has been amended over time, based on new insights. The anatomical names and delineations of the cortical regions have therefore changed in the newer editions of the atlas of Paxinos and Watson (2005). In the reviewed studies, we have relied on the authors' description of the injection sites and projections to the STN, since detailed anatomical pictures were often lacking.

\section{Conclusion}

A partial anatomical subdivision system is present in the rodent STN, although it is not as clear cut as in the primate. Neurons in the medial STN mainly get their afferent input from the limbic and associative cortical areas and those in the lateral two thirds receive their input from the motor areas. 


\section{REFERENCES}

Afsharpour, S., 1985. Topographical projections of the cerebral cortex to the subthalamic nucleus. The J. Comp. Neurol. 236, 14-28.

Benazzouz, A., Breit, S., Koudsie, A., Pollak, P., Krack, P., Benabid, A.L., 2002. Intraoperative microrecordings of the subthalamic nucleus in Parkinson's disease. Mov. Disord. 17 Suppl 3, S145-149.

Berendse, H.W., Groenewegen, H.J., 1990. Organization of the thalamostriatal projections in the rat, with special emphasis on the ventral striatum. J. Comp. Neurol. 299, 187-228.

Berendse, H.W., Groenewegen, H.J., 1991. The connections of the medial part of the subthalamic nucleus in the rat: evidence for a parallel organization. The basal ganglia III New York: Plenum 89-98.

Bergman, H., Wichmann, T., Karmon, B., DeLong, M.R., 1994. The primate subthalamic nucleus. II. Neuronal activity in the MPTP model of parkinsonism. J. Neurophysiol. 72, 507-520.

Canteras, N.S., Shammah-Lagnado, S.J., Silva, B.A., Ricardo, J.A., 1988. Somatosensory inputs to the subthalamic nucleus: a combined retrograde and anterograde horseradish peroxidase study in the rat. Brain Res. 458, 53-64.

Canteras, N.S., Shammah-Lagnado, S,J., Silva, B.A., Ricardo, J.A., 1990. Afferent connections of the subthalamic nucleus: a combined retrograde and anterograde horseradish peroxidase study in the rat. Brain Res. 513, 43-59.

Carpenter, M.B., Carleton, S.C., Keller, J.T., Conte, P., 1981. Connections of the subthalamic nucleus in the monkey. Brain Res. $224,1-29$.

Degos, B., Deniau, J.M., Le Cam, J., Mailly, P., Maurice, N., 2008. Evidence for a direct subthalamo-cortical loop circuit in the rat. Eur. J. Neurosci. 27, 2599-2610.

Donoghue, J.P., Wise, S.P., 1982. The motor cortex of the rat: cytoarchitecture and microstimulation mapping. J. Comp. Neurol. 212 , 76-88.

Dostrovsky, J.O., Lozano, A.M., 2002. Mechanisms of deep brain stimulation. Mov. Disord. 17 Suppl 3, S63-68.

Fujimoto, K., Kita, H., 1993. Response characteristics of subthalamic neurons to the stimulation of the sensorimotor cortex in the rat. Brain Res. $609,185-192$.

Gerfen, C.R., 1985. The neostriatal mosaic. I. Compartmental organization of projections from the striatum to the substantia nigra in the rat. J. Comp. Neurol. 236, 454-476.

Gradinaru, V., Mogri, M., Thompson, K.R., Henderson, J.M., Deisseroth, K., 2009. Optical Deconstruction of Parkinsonian Neural Circuitry. Science (New York, NY.2009).

Groenewegen, H.J., Berendse, H.W., 1990. Connections of the subthalamic nucleus with ventral striatopallidal parts of the basal ganglia in the rat. J. Comp. Neurol. 294, 607-622.

Hall, R.D., Lindholm, E.P., 1974. Organization of the motor and somatosensory neocortex in the albino rat. . Brain Res. $66,23-38$.

Hamani, C., Saint-Cyr, J.A., Fraser, J., Kaplitt, M., Lozano, A.M., 2004. The subthalamic nucleus in the context of movement disorders. Brain. $127,4-20$.

Hameleers, R., Temel, Y., Visser-Vandewalle, V., 2006. History of the corpus luysii: 1865-1995. Arch. Neurol. 63, 1340-1342.

Hardman, C.D., Henderson, J.M., Finkelstein, D.I., Horne, M.K., Paxinos, G., Halliday, G.M., 2002. Comparison of the basal ganglia in rats, marmosets, macaques, baboons, and humans: volume and neuronal number for the output, internal relay, and striatal modulating nuclei. J. Comp. Neurol. 445, 238-255.

Heimer, L., Alheid, G.F., Zahm, D.S., 1995. Basal ganglia. In: The rat nervous system (Paxinos, G., ed), pp 579-628: Academic Press Inc., San Diego.

Jurgens, U., 1984. The efferent and afferent connections of the supplementary motor area. Brain Res. 300, 63-81.

Kita, H., Kitai, S.T., 1987. Efferent projections of the subthalamic nucleus in the rat: light and electron microscopic analysis with the PHA-L method. J. Comp. Neurol. 260, 435-452.

Kitai, S.T., Deniau, J.M., 1981. Cortical inputs to the subthalamus: intracellular analysis. Brain Res. 214, $411-415$.

Kleiner-Fisman, G., Herzog, J., Fisman, D.N., Tamma, F., Lyons, K.E., Pahwa, R., Lang, A.E., Deuschl, G., 2006. Subthalamic nucleus deep brain stimulation: summary and meta-analysis of outcomes. Mov. Disord. 21 Suppl 14, S290-304.

Kolomiets, B.P., Deniau, J.M., Mailly, P., Menetrey, A., Glowinski, J., Thierry, A.M., 2001. Segregation and convergence of information flow through the cortico-subthalamic pathways. J. Neurosci. 21, 5764-5772.

Krack, P., Batir, A., Van Blercom, N., Chabardes, S., Fraix, V., Ardouin, C., Koudsie, A., Limousin, P.D., Benazzouz, A., LeBas, J.F., Benabid, A.L., Pollak, P., 2003. Five-year follow-up of bilateral stimulation of the subthalamic nucleus in advanced Parkinson's disease. N.E.J.M. 349, 1925-1934.

Kunzle, H., 1978. An autoradiographic analysis of the efferent connections from premotor and adjacent prefrontal regions (areas 6 and 9) in macaca fascicularis. Brain, behavior and evolution. 15, 185-234.

Leichnetz, G.R., Hardy, S.G., Carruth, M.K., 1987. Frontal projections to the region of the oculomotor complex in the rat: a retrograde and anterograde HRP study. J. Comp. Neurol. 263, 387-399.

Magill, P.J., Bolam, J.P., Bevan, M.D., 2000. Relationship of activity in the subthalamic nucleus-globus pallidus network to cortical electroencephalogram. J. Neurosci. 20, 820-833.

Magill, P.J., Sharott, A., Bevan, M.D., Brown, P., Bolam, J.P., 2004. Synchronous unit activity and local field potentials evoked in the subthalamic nucleus by cortical stimulation. J. Neurophysiol. 92, 700-714.

Maurice, N., Deniau, J.M., Glowinski, J., Thierry, A.M., 1998. Relationships between the prefrontal cortex and the basal ganglia in the rat: physiology of the corticosubthalamic circuits. J. Neurosci. 18, 9539-9546.

Monakow, K.H., Akert, K., Kunzle, H., 1978. Projections of the precentral motor cortex and other cortical areas of the frontal lobe to the subthalamic nucleus in the monkey. Exp. Brain Res. Experimentelle Hirnforschung. 33, 395-403.

Nambu, A., Takada, M., Inase, M., Tokuno, H., 1996. Dual somatotopical representations in the primate subthalamic nucleus: evidence for ordered but reversed body-map transformations from the primary motor cortex and the supplementary motor area. J. Neurosci. 16, 26712683.

Nambu, A., Tokuno, H., Hamada, I., Kita, H., Imanishi, M., Akazawa, T., Ikeuchi, Y., Hasegawa, N., 2000. Excitatory cortical inputs to pallidal neurons via the subthalamic nucleus in the monkey. J. Neurophysiol. 84, 289-300.

Nambu, A., Tokuno, H., Inase, M., Takada, M., 1997. Corticosubthalamic input zones from forelimb representations of the dorsal and ventral divisions of the premotor cortex in the macaque monkey: comparison with the input zones from the primary motor cortex and the supplementary motor area. Neuroscience letters. 239,13-16.

Nambu, A., Tokuno, H., Takada, M., 2002. Functional significance of the cortico-subthalamo-pallidal 'hyperdirect' pathway. Neurosci. Res. 43, 111-117. 
Ni, Z.G., Bouali-Benazzouz, R., Gao, D.M., Benabid, A.L., Benazzouz, A., 2001. Time-course of changes in firing rates and firing patterns of subthalamic nucleus neuronal activity after 6-OHDA-induced dopamine depletion in rats. Brain Res. 899, 142-147.

Orieux, G., Francois, C., Feger, J., Hirsch, E.C., 2002. Consequences of dopaminergic denervation on the metabolic activity of the cortical neurons projecting to the subthalamic nucleus in the rat. J. Neurosci. 22, 8762-8770.

Parent, A., Hazrati, L.N., 1995. Functional anatomy of the basal ganglia. I. The cortico-basal ganglia-thalamo-cortical loop. Brain Res. Rev. 20, 91-127.

Parent, A., Hazrati, L.N., 1995. Functional anatomy of the basal ganglia. II. The place of subthalamic nucleus and external pallidum in basal ganglia circuitry. Brain Res. Rev. 20, 128-154.

Paxinos, G., Watson, C., (eds) 1986. The rat brain in stereotaxic coordinates. New York: Acadmic Press.

Paxinos, G., Watson, C., (eds.) 1998. The rat brain in stereotaxic coordinates

New York: Academic Press.

Paxinos, G., Watson, C., (eds.) 2005. The rat brain in stereotaxic coordinates

New York: Academic Press.

Reiner, A., Veenman, C.L., Medina, L., Jiao, Y., Del Mar, N., Honig, M.G., 2000. Pathway tracing using biotinylated dextran amines. J. Neurosci. methods. 103, 23-37.

Ricardo, J.A., 1980. Efferent connections of the subthalamic region in the rat. I. The subthalamic nucleus of Luys. Brain Res. 202, $257-271$.

Rodriguez-Oroz, M.C., Zamarbide, I., Guridi, J., Palmero, M.R., Obeso, J.A., 2004. Efficacy of deep brain stimulation of the subthalamic nucleus in Parkinson's disease 4 years after surgery: double blind and open label evaluation. J. Neurol., J. Neurosurg., J. Psychiat. 75, $1382-1385$.

Rouzaire-Dubois, B., Scarnati, E., 1985. Bilateral corticosubthalamic nucleus projections: an electrophysiological study in rats with chronic cerebral lesions. Neurosci. 15, 69-79.

Strafella, A.P., Vanderwerf, Y., Sadikot, A.F., 2004. Transcranial magnetic stimulation of the human motor cortex influences the neuronal activity of subthalamic nucleus. Eur. J. Neurosci. 20, 2245-2249.

Sugimoto, T., Hattori, T., Mizuno, N., Itoh, K., Sato, M., 1983. Direct projections from the centre median-parafascicular complex to the subthalamic nucleus in the cat and rat. J. Comp. Neurol. 214, 209-216.

Temel, Y., Blokland, A., Steinbusch, H.W., Visser-Vandewalle, V., 2005. The functional role of the subthalamic nucleus in cognitive and limbic circuits. Prog. Neurobiol. 76, 393-413.

Temel, Y., Kessels, A., Tan, S., Topdag, A., Boon, P., Visser-Vandewalle, V., 2006. Behavioural changes after bilateral subthalamic stimulation in advanced Parkinson disease: a systematic review. Parkinsonism Relat D. 12, 265-272.

Tsumori, T., Yokota, S., Kishi, T., Qin, Y., Oka, T., Yasui, Y., 2006. Insular cortical and amygdaloid fibers are in contact with posterolateral hypothalamic neurons projecting to the nucleus of the solitary tract in the rat. Brain Res. 1070, 139-144.

Visser-Vandewalle, V., Van der Linden, C., Temel, Y., Celik, H., Ackermans, L., Spincemaille, G., Caemaert, J., 2005. Long-term effects of bilateral subthalamic nucleus stimulation in advanced Parkinson disease: a four year follow-up study. Parkinsonism Relat. D. 11, 157-165.

Voon, V., Krack, P., Lang, A.E., Lozano, A.M., Dujardin, K., Schupbach, M., D’Ambrosia, J., Thobois, S., Tamma, F., Herzog, J., Speelman, J.D., Samanta, J., Kubu, C., Rossignol, H., Poon, Y.Y., Saint-Cyr, J.A., Ardouin, C., Moro, E., 2008. A multicentre study on suicide outcomes following subthalamic stimulation for Parkinson's disease. Brain. 131, 2720-2728.

Wan, X.S., Liang, F., Moret, V., Wiesendanger, M., Rouiller, E.M., 1992. Mapping of the motor pathways in rats: c-fos induction by intracortical microstimulation of the motor cortex correlated with efferent connectivity of the site of cortical stimulation. Neurosci. 49, 749-761.

Kawamura, Y., Fujiwara, H., Mishima, N., Tanaka, Y., Tanimoto, A., Ikawa, S., Itoh Y., Ezaki, T., 2003. First streptococcus agalactiae isolates highly resistant to quinolones, with point mutations in gyrA and parC. Antimicrob. Agents Ch. 47, 3605-3609

Kraśnianin, E., Skret-Magierło, J., Witalis, J., Barnaś, E., Kluz, T., Kozieł, A., Skret, A., 2009. The incidence of streptococcus group b in 100 parturient women and the transmission of pathogens to the newborn. Ginekol. Pol. 80, 285-289.

Kulkarni, A.A., Pawar, S.G., Dharmadhikari, C.A., Kulkarni, R.D., 2001. Colonization of pregnant women and their newborn infants with group-B streptococci. Indian J. Med. Microbi. 19, 1-4.

Money, D.M., Dobson, S., 2004. The prevention of early-onset neonatal group B streptococcal disease. J. Obstet. Gynaecol. Can. 26 , 826-832.

Monique, T.S., Jan, K., Louis, K., Bakkers, J., Melchers, W., Spanjaard, L., Wannet, W.J., Hoogkamp-Korstanje, M.A., 2006. Serotypes, geno types and antibiotic susceptibility profiles of group B streptococci causing neonatal sepsis and meningitisbefore and after introduction of antibiotic prophylaxis. Pediatr. Infect. Dis. J. 25, 945-948.

Moyo, S.R., Maeland, J.A., Bergh, K., 2002. Typing of human isolates of streptococcus agalactiae (group B streptococcus, gbs) strains from Zimbabwe. J. Med. Microbiol. 51, 595-600.

Ölçü, M., Eşel, D., 2007. Antibiotic susceptibilities of clinical streptococcus agalactiae isolates. J. Health Sci. 16, 23-27.

Schrag, S.J., Phil, D., Zywicki, S. Farley, M.M., Reingold, A.L., Harrison, L.H., Lefkowitz, L.B., Hadler, J.L., Danila, R., Cieslak, P.R., Schuchat, A., 2000. Group B streptococcal disease in the era of intrapartum antibiotic prophylaxis. N. Engl. J. Med. 342, 15-20.

Topkaya, A., Küçükercan, M., Oğuzoğlu, N., Ünal, N., Narin, K., 2003. Antibiotic susceptibilities of group B streptococci isolated from vaginal and rectal colonization in pregnant women. J. Turk. Microbi. Society. 33, 242-245.

Tünger, A., Çavuşoğlu, C., Korkmaz, M. 2005. Group B streptococcus. Asya Microbi. 94-96.

Quiroga, M., Pegels, E., Oviedo, P., Pereyra, E., Vergara, M., 2008. Antibiotic susceptibility patterns and prevalence of group B streptococcus isolated from pregnant women in misiones, Argentina. Brazilian J. Microbi. 39, 245-25. 